\title{
Nanoscale Investigation and Control of Photothermal Action of Gold Nanostructure-coated Surfaces
}

\section{Samir V Jenkins}

University of Arkansas for Medical Sciences https://orcid.org/0000-0003-1496-2035

\section{Seunghyun Jung}

University of Arkansas for Medical Sciences

\section{Shruti Shah}

University of Arkansas for Medical Sciences

\section{Paul C Millett}

University of Arkansas Fayetteville

\section{Ruud P.M. Dings}

University of Arkansas for Medical Sciences

\section{Michael J. Borrelli}

University of Arkansas for Medical Sciences

\section{Robert J. Griffin ( $\nabla$ rjgriffin@uams.edu )}

Departments of Radiation Oncology, University of Arkansas for Medical Sciences, Little Rock AR https://orcid.org/0000-0002-3574-2958

\section{Research}

Keywords: Gold nanoparticles, Thermal dose, Photothermal, Cell-culture surfaces

Posted Date: September 23rd, 2020

DOI: https://doi.org/10.21203/rs.3.rs-76256/v1

License: (c) (i) This work is licensed under a Creative Commons Attribution 4.0 International License. Read Full License

Version of Record: A version of this preprint was published at Journal of Materials Science on March 8th, 2021. See the published version at https://doi.org/10.1007/s10853-021-05947-6. 
1 Nanoscale Investigation and Control of Photothermal Action of Gold Nanostructure-coated

2 Surfaces

3 Samir V. Jenkins, ${ }^{1}$ Seunghyun Jung, ${ }^{2}$ Shruti Shah, ${ }^{1}$ Paul C. Millett, ${ }^{3}$ Ruud P.M. Dings, ${ }^{1}$ Michael

4 J. Borrelli, ${ }^{4}$ Robert J. Griffin ${ }^{1 *}$

5

6 Departments of ${ }^{1}$ Radiation Oncology, ${ }^{2}$ Physiology, and ${ }^{4}$ Radiology; University of Arkansas for

7 Medical Sciences, Little Rock AR

$8 \quad{ }^{3}$ Department of Mechanical Engineering, University of Arkansas, Fayetteville, AR

$9 \quad *$ *Corresponding Author: Robert J. Griffin (rjgriffin@uams.edu, F: 5016867285)

11 Keywords: Gold nanoparticles, Thermal dose, Photothermal, Cell-culture surfaces,

12 Abstract

13 Background: The combination of biological variation and nanomaterial heterogeneity makes

14 elucidating the mechanisms of interactions between cells and nanoparticles extremely

15 complicated. Accurate nanoparticle quantification can be extremely challenging, and cellular

16 response can change based on the location of the nanoparticle and the cell type under investigation.

17 These complications are only augmented by the additional of external stimuli. These limitations

18 have yielded a wide range of studies that show effects, but often provide little mechanistic insight.

19 Results: Gold nanomaterials were stably immobilized onto glass coverslips treated with

20 mercaptosilane to control both the average number of nanoparticles that interact with cells and

21 their spatial orientation relative to the cell membrane. Surfaces were characterized optically and

22 by electron microscopy to confirm their surface density and uniformity. The thermal response of

$23 \mathrm{Au}$ nanocage-coated surfaces to near infrared laser irradiation was measured in cell culture 
24 medium and modelled computationally. The modelling showed a vastly higher thermal dose than

25 would be predicted by bulk temperature measurements. Adherent or non-adherent cell lines were

26 cultured directly on the nanocage-coated surface or in the medium, respectively, in culture wells

27 and laser irradiation was applied. Survival of cells growing in suspension correlated with the bulk

28 temperature increase in the culture medium, as measured by viability assay. Conversely, adherent

29 cells exhibited a much greater susceptibility than expected from the bulk temperature

30 measurement, which is ostensibly related to the close interaction with the nanoparticles on their

31 growth substrate and induction of substantially greater thermal dose upon laser exposure.

32 Conclusions: This platform is designed to be a new tool to determine how many particles need to

33 be in contact with a cell to induce desired physical or biological effects. Here we demonstrate the 34 delivery of precise thermal doses following laser irradiation. The anticipated biological effects

35 based on bulk measurements vastly underestimated the effects that were observed, which is 36 ascribed to the proximity of the nanoparticle to the cell and the extraordinary high surface 37 temperature of the particle. This platform could be expanded to a variety of nanoparticles, external 38 stimuli, and cell types to enable more deliberate and optimized application of nanomedicine. 


\section{Background}

Local thermal therapy is an attractive, emerging treatment modality for biomedical

42 conditions requiring sterilization or ablation of pathological tissue features. This localized

43 treatment can be precisely delivered by combining absorbing nanoparticles with optical or

44 magnetic ${ }^{1}$ fields. Plasmonic nanoparticles, particularly gold-based particles (AuNPs), are under

45 intense investigation as thermal transducers due to their strong electromagnetic absorption, ${ }^{2}$

46 biocompatibility, ${ }^{3}$ surface functionalizability, ${ }^{4}$ and potential for on-demand drug delivery. ${ }^{5}$

47 However, there is a paucity of methods to determine precise effects due to heterogeneous

48 biological responses in culture or tissues and from nanoparticle composition variability. Setting

49 aside the myriad complexities involved in in vivo systems, there is a vast degree of heterogeneity

50 even at a cellular level. The cell association values (i.e. the number of particles per cell) are

51 typically calculated after incubation with the particles. This alone has been demonstrated to show

52 a wide Gaussian curve of particle number per cell using means such as single particle ICP-MS,

53 flow cytometry, and optical and electron microscopy. ${ }^{6-8}$ This limitation is further complicated by

54 the cellular localization of particles, which may be membrane bound, ${ }^{9}$ cytosolic, ${ }^{10}$ endosomally

55 encapsulated, ${ }^{11}$ nuclear $^{12}$ or some combination thereof. Additionally, these measurements require

56 multiple preparatory steps to ascertain final values, which include collection of cells, washing, and

57 work-up. As a result, the quantification of the particle association with cells is indirect and

58 experimentally averaged. Technical limitations severely impede the ability to directly measure

59 these materials microscopically in situ in a large, statistically-relevant population. ${ }^{13}$ In addition to

60 these preparatory steps, the variable distribution of particles per cell further modulates the dose

61 received by individual cells. ${ }^{14}$ Even the determination of particle concentration prior to incubation

62 is a challenging task that can affect outcomes. ${ }^{15}$ Ultimately the dose is treated as a bulk average. 
63 This issue is akin to the distinction between bulk optical properties and single-molecule studies. ${ }^{16}$ 64 As a result of these factors, correlating the in vitro dose at the level of the particle vs. the bulk 65 culture becomes a largely arbitrary and unreliable endeavor.

67 means of achieving local nanomaterial therapeutic effects. ${ }^{17}$ To date, characterizing the response

68 to laser-induced nanoparticle heating generally relies on indirect evidence via bulk solution temperature measurements. An ongoing challenge for the validation of the mechanism of action

70

71

72

73

74

75

76

77

78

79

80

81

82

83

84

85

of these materials upon non-invasive stimulation by light is the determination of true "thermal dose." Thermal dose can be practically defined as the amount of heat received by an individual cell or particular volume in a given time. ${ }^{18,19}$ Traditional non-ablative hyperthermic treatment uses multi-hour heating with a temperature change of only a few degrees above body temperature $(<43$ $\left.{ }^{\circ} \mathrm{C}\right) .{ }^{20}$ Conversely, many nanoparticle heating studies utilize extremely short heating durations caused by rapid absorption of pulses of light with analogous bulk temperature changes. ${ }^{21}$ While the temperature changes and therapeutic outcomes are often similar, the difference in the time*temperature product - which estimates thermal dose $\mathrm{e}^{22}$ - strongly suggests dramatic divergences among local heating effects. The most common thermal dose metric is the cumulative equivalent minutes at $43{ }^{\circ} \mathrm{C}$ (CEM43). ${ }^{23,24}$ Further, numerous studies have shown that cell-specific targeting leads to greatly enhanced 'thermal' effects relative to similar temperature profiles with untargeted particles. ${ }^{25}$ A variety of pre-clinical studies have observed distinctly different effects between untargeted materials and targeted materials using ligands for $\alpha 1 \beta \mathrm{v},{ }^{26}$ epithelial growth factor receptor, ${ }^{27}$ or galectin- $1,{ }^{28,29}$ and this has been further demonstrated in vitro in bacterial biofilm models. ${ }^{30}$ It is under debate whether this enhancement is the result of increased accumulation, minimal spatial separation of particles and cells, or a combination thereof. As such, 
86 the resultant cellular response to photothermal stress would not be anticipated based purely on

87 bulk temperature effects. ${ }^{31}$ The extreme variance on a per cell basis regarding particle uptake

88 combined with the relatively extreme heating at the nanoparticle surface (a highly irregular

89 time/temperature history $)^{32}$ limits the mechanistic utility of many in vitro studies, and both

90 measuring and calculating these temperatures are nontrivial tasks. ${ }^{33}$ As a result, the precise

91 response to these extreme heating conditions is not well understood experimentally.

92 Toward the end of thoroughly understanding and controlling nanoparticle induced heat

93 effects, this report demonstrates a novel nanomaterial validation platform that employs

94 nanomaterial coated surfaces to induce, characterize, and apply precise thermal doses to cells

95 cultured upon them. This method's utility was demonstrated with a variety of nanoparticle

96 morphologies including Au nanocages (AuNCs), nanorods (AuNRs), and nanospheres (AuNSs).

97 Indeed, these particles function like very small heaters upon laser irradiation and induce biological

98 effects on nearby, attached cells to a much different extent than bulk temperature would suggest,

99 which was validated with theoretical modelling. This change in heating was demonstrated through

100 photothermal killing of adherent cells, while under identical conditions suspension cells were

101 minimally affected. The different biological outcomes despite similar temperature measurements

102 are discussed, providing a context for similar studies that rely on strong local effects from

103 nanoparticles themselves, such as drug delivery or ionizing radiation enhancement.

104 Materials and Methods

105 Reagents

106 Silver trifluoroacetate (AgTFA), sodium hydrogen sulfide $(\mathrm{NaSH})$, hydrochloric acid $(\mathrm{HCl}$, $10799.999 \%)$, tetrachloroauric acid trihydrate $\left(\mathrm{HAuCl}_{4} \cdot 3 \mathrm{H}_{2} \mathrm{O}\right)$, sodium chloride $(\mathrm{NaCl})$, and were 108 purchased from Alfa Aesar. Poly(vinylpyrrolidone) (PVP, M.W.=55,000), sodium carbonate 
$109\left(\mathrm{Na}_{2} \mathrm{CO}_{3}\right)$, sodium bicarbonate $\left(\mathrm{NaHCO}_{3}\right)$, methanol $(\mathrm{MeOH})$ concentrated sulfuric acid $\left(\mathrm{H}_{2} \mathrm{SO}_{4}\right)$, 110 nitric acid $\left(\mathrm{HNO}_{3}\right)$, hydrochloric acid $(\mathrm{HCl})$, and $30 \%$ hydrogen peroxide $\left(\mathrm{H}_{2} \mathrm{O}_{2}\right)$, 3111 aminopropyltrismethoxysilane (APTMS), and 3-mercaptopropyltrismethoxysilane (MPTMS) 112 were purchased from Sigma Aldrich. Ethylene glycol (EG) was purchased from J.T. Baker. 113 Acetone was purchased from EMD. Au nanospheres, nanorods, and nanocubes were purchased 114 from Nanocomposix (San Diego). All experiments were performed using $18 \mathrm{M} \Omega \mathrm{H} 2 \mathrm{O}$ unless 115 specified otherwise. All chemicals were used as received.

116 AuNC Preparation

117 AuNCs were synthesized using the galvanic replacement reaction between the Ag nanocubes and 118 tetrachloroauric acid in aqueous solution modified from previous publications. ${ }^{34} \mathrm{The} \mathrm{Ag}$ 119 nanocubes were prepared by the modified polyol process. Briefly, ethylene glycol (EG; $50 \mathrm{ml})$ 120 was added into a $250 \mathrm{ml}$ round bottom flask and heated to $150{ }^{\circ} \mathrm{C}$ in air, without a condenser. To 121 the reaction, $3 \mathrm{mM} \mathrm{NaSH}$ in $\mathrm{EG}(0.6 \mathrm{ml}), 3 \mathrm{mM} \mathrm{HCl}$ in $\mathrm{EG}(5 \mathrm{ml}), 180 \mathrm{mM}$ polyvinylpyrrolidone 122 (PVP; $12.5 \mathrm{ml}$ ) and $325 \mathrm{mM}$ silver trifluoroacetate $(4 \mathrm{ml})$ were added into the preheated EG in the 123 above sequence. The color of the reaction changed from yellow to dark red, reddish grey and 124 brown, indicating the formation of the Ag nanocubes with desired edge length (35-40 nm) and 125 LSPR $~ 430 \mathrm{~nm}$. The Ag nanocubes were collected by centrifugation, purified with acetone and 126 resuspended in $10 \mathrm{ml}$ of water. For the galvanic replacement, the Ag nanocubes ( $2 \mathrm{ml})$ were added 127 to $20 \mathrm{ml}$ of boiling $\mathrm{H}_{2} \mathrm{O}$. After the solution re-established thermal equilibrium ( 2 $\left.\min \right), 1 \mathrm{mM}$ $128 \mathrm{HAuCl}_{4}$ aqueous solution was titrated at a rate of $45 \mathrm{ml} / \mathrm{h}$ until the absorbance maximum reached $129800 \mathrm{~nm}$. The solution was kept on heat for another $5 \mathrm{~min}$, and then allowed to cool to room 130 temperature. This process was repeated for several batches, which were ultimately combined. The 
131 resultant $\mathrm{AuNCs}$ were washed with saturated $\mathrm{NaCl}$ to solubilize $\mathrm{AgCl}$ and subsequently three times

132 with water.

133 Surface Preparation

134 Surface preparation for AuNC coated surfaces was achieved as follows. Necessary adjustments

135 for other AuNP morphologies are found in Table 1. Glass cover slips (circular, 12.5 mm diameter)

136 were initially pretreated with aqua regia $\left(3: 1 \mathrm{HCl}: \mathrm{HNO}_{3}\right)$ then treated for $60 \mathrm{~min}$ at $60-65^{\circ} \mathrm{C}$ with

137 piranha solution $\left(3: 1 \mathrm{H}_{2} \mathrm{SO}_{4}: \mathrm{H}_{2} \mathrm{O}_{2}\right)$ in glass petri dishes. (NOTE: Piranha solution is extremely

138 corrosive and must be handled cautiously with adequate PPE including goggles, lab coat, and

139 gloves). The reaction was quenched with 2 washes with $\mathrm{DI} \mathrm{H}_{2} \mathrm{O}$, followed by 2 rinses with $100 \%$

$140 \mathrm{MeOH}$. Surfaces were then submerged in $\mathrm{MeOH}$ with 10\% (trismethoxy)-mercaptopropyl silane

141 for $60-72 \mathrm{~h}$ at $37{ }^{\circ} \mathrm{C}$. Surfaces were then washed thrice with $100 \% \mathrm{MeOH}$ and set in individual

142 wells of a 24 -well plate that contains $1 \mathrm{~mL}$ of $100 \% \mathrm{MeOH}$. The 24 well plate containing the

143 silanized coverslips was sonicated in a bath sonicator (Fisher) for $10 \mathrm{~min}$. Surfaces were washed

144 twice with $100 \% \mathrm{MeOH}$. The glass coverslips were cured at $100{ }^{\circ} \mathrm{C}$ for $5 \mathrm{~min}$. Au nanoparticles

145 were added in varying aqueous buffers and concentrations in $1 \mathrm{~mL}$ and the reaction was allowed

146 to proceed overnight at $37^{\circ} \mathrm{C}$. The best results were obtained with AuNCs $(6.4,12.8$, or 25.6 fmol

147 in $1 \mathrm{~mL})$ added to sodium carbonate-bicarbonate buffer $(\mathrm{pH}=9.1,5 \mathrm{mM})$ Surfaces were then

148 washed with DI $\mathrm{H}_{2} \mathrm{O}$ and allowed to dry in the plate. Sterilization was achieved by removing the

149 lid from the plate in a biosafety cabinet and running the UV cycle.

150 Surface Characterization

151 The specimens deposited on glass slides were mounted onto $12.2 \mathrm{~mm}$ dia. x10 mm high aluminum

152 disks (Ted Pella, Inc. Redding, CA) by double sided carbon tapes, and their surfaces were covered

153 by $\sim 3 \mathrm{~nm}$ thick carbon films as conductive coatings. The carbon films were deposited by Gatan 
154681 Ion Beam Coater (Gatan, Inc. Pleasanton, CA). The specimens were then mounted on a 155 stainless steel specimen holder, and their edges were grounded to the holder by conductive copper 156 tapes. before being inserted into a JEOL JSM-7000F (JEOL USA, Peabody, MA) field emission 157 scanning electron microscope (SEM). A series of secondary electron images with varying 158 magnifications on each specimen were obtained at specimen bias ranging from $5 \mathrm{kV}$ to $15 \mathrm{kV}$.

\section{Cell Culture}

160 4T1 (murine breast carcinoma) and EL4 (murine leukemia) cells were purchased from ATCC (Cat. 161 No. CRL-2539 and TIB-39). Cells were cultured in DMEM containing 10\% FBS and 1\% P/S and 162 passaged biweekly. Cells were incubated at $37{ }^{\circ} \mathrm{C}$, with $90 \%$ humidity and $5 \% \mathrm{CO}_{2}$.

\section{Photothermal Treatment}

164 Surfaces in wells were covered with $1 \mathrm{~mL}$ of cell culture media prior to laser application. The laser 165 spot size was adjusted to $12.5 \mathrm{~mm}$ diameter, and the power was adjusted to control fluence. 166 Temperature measurements were taken with a thermal couple applied directly to the coverslip at 2 167 min intervals, during which laser illumination was briefly halted $(<5 \mathrm{sec})$.

168 4T1 cells were seeded at 5000 cells per well in a $200 \mu \mathrm{L}$ drop on the sterilized particle-coated 169 surface. After being allowed to adhere for $3 \mathrm{~h}$, an additional $800 \mu \mathrm{L}$ of media was added to bring 170 the final volume to $1 \mathrm{~mL}$. EL4 cells were directly applied as 5000 cells in $1 \mathrm{~mL}$. The plates were 171 allowed to equilibrate to room temperature for $30 \mathrm{~min}$ prior to laser application. Laser irradiation 172 was applied using a Diomed 25 at $808 \mathrm{~nm}$ with a fluence of $0.75 \mathrm{~W} / \mathrm{cm}^{2}$ for $10 \mathrm{~min}$. Cells were 173 then returned to incubation at $37^{\circ} \mathrm{C}$ and allowed to grow for 3 days prior to measurement of cell 174 viability via CCK-8 assay (Dojindo). All cell viability measurements were normalized to cells 175 grown on standard tissue culture wells without glass surfaces or laser treatment and run in 176 triplicate. 
177 For bulk heating experiments, cells were seeded at 1000 cells/well in standard tissue culture 96-

178 well plates. After 3 hours, plates were sealed with parafilm, enclosed in plastic bags and submerged

179 in a circulating water bath (Thermo DC10) at $37-50{ }^{\circ} \mathrm{C}$ for $10 \mathrm{~min}$ (or $1 \mathrm{~h}$ at $42.5^{\circ} \mathrm{C}$ ). Plates were

180 unsealed and returned to the incubator following treatment and viability was measured after 3 days

181 using CCK-8.

\section{Theoretical Modelling}

183 The temperature distribution resulting from the photothermal excitation of a nanoparticle (or a 184 system of nanoparticles) can be modeled with the standard heat transfer equation:

185

$c \rho \frac{\partial T(\boldsymbol{r}, t)}{\partial t}=k \frac{\partial^{2} T(\boldsymbol{r}, t)}{\partial \boldsymbol{r}^{2}}+Q(\boldsymbol{r}, t)$

186 where $T(\boldsymbol{r}, t)$ is the coordinate- and time-dependent temperature, $Q(\boldsymbol{r}, t)$ is the volumetric heat

187 source term (units of $\mathrm{W} / \mathrm{m}^{3}$ ), and $c, \rho$, and $k$ are the heat capacity, density, and thermal 188 conductivity of the medium, respectively. Following Govorov et al. ${ }^{35}$ the steady-state temperature 189 profile extending radially from a single (spherical) nanoparticle heat source is:

$190 \Delta T_{o}(\boldsymbol{r})=\frac{V_{N P} Q}{4 \pi k r}\left(r>R_{N P}\right)$

191 where $R_{N P}$ and $V_{N P}$ are the radius and volume of the nanoparticle. Govorov et al. further considered 192 a superstructure of $N_{N P}$ nanoparticle heat sources arranged in $m$-dimensional space, for which the temperature distribution was derived as (for $m \geq 2$ ):

$194 \Delta T(\boldsymbol{r}) \approx \Delta T_{o}(\boldsymbol{r}) \frac{R_{N P}}{p} N_{N P}^{(m-1) / m}$

195 where $p$ is the average spacing between nanoparticles. ${ }^{35}$ For this work, we assume $m=2$ and the 196 thermal conductivity of water $=0.6 \mathrm{~W} / \mathrm{m} / \mathrm{K}=6 \mathrm{e}-7 \mathrm{~W} / \mu \mathrm{m} / \mathrm{K}$.

197 Calculation of CEM43 values was performed using 198

$C E M 43=\sum_{i=1}^{n} t_{i} \times R^{\left(43-T_{i}\right)}$ 
where CEM43 is the cumulative number of equivalent minutes at $43{ }^{\circ} \mathrm{C}, t$ is time, $T_{i}$ is temperature at the $i$-th time interval, and $R$ is related to the temperature dependence of cell death such that when $T_{i}<43{ }^{\circ} \mathrm{C}, R=1 / 4$ and when $T_{i}>43{ }^{\circ} \mathrm{C} R=1 / 2 .{ }^{23}$ In Eq. (4), $T_{i}$ values were determined based on the average temperature from 0.05 to $5 \mu \mathrm{m}$ as determined by Eq. (3).

\section{Results}

AuNCs were synthesized and found to be $>99 \%$ cubic nanostructures with an edge length of approximately $50 \mathrm{~nm}$. AuNCs were coated onto glass coverslips according to Scheme 1. It was found that a crucial step in the synthetic process was the rapid (within several minutes) use of silanized coverslips following either methanol washing or storage in methanol. These materials were found to be stable during washing with $\mathrm{H}_{2} \mathrm{O}$ and resistant to solvents such as ethanol (70\%) and dimethyl sulfoxide (DMSO). They were visually uniform (Fig. 1A) and showed an even distribution under optical microscopy (Fig. 1B-E), despite the presence of some salt crystals, and they demonstrated a coverage dependent extinction (Fig. 1F).

AuNCs were used for further studies as they were found to be the most synthetically cooperative materials at the outset of experiments. Additionally, AuNCs have been found to have larger extinction coefficients than AuNRs and AuNSs, particularly at the $808 \mathrm{~nm}$ laser wavelength used. Scanning electron microscopy images showed a highly uniform surface coverage and varying the initial AuNC quantity from 6.4 to 12.8 and $25.6 \mathrm{fmol}$ AuNC yielded coverage of $20 \pm$ 2, $32 \pm 2$, and $54 \pm 2 \mathrm{AuNC} / \mu \mathrm{m}^{2}$, respectively (Fig. 2). Based on the area of the coverslip (122.7 $\mathrm{mm}^{2}$ ) the deposition efficiency was $64 \%, 51 \%$, and $43 \%$ respectively. This number does not include regions of spontaneous flocculation on the surface, which would significantly increase the calculated deposition efficiency. 
222 the course of the first 8 hours, which was followed by a much slower deposition phase over the 223 next 5 days. The process could be monitored spectroscopically (Fig. 3A), and the increase in 224 particle coverage density was confirmed using SEM (Fig. 3B-C). When taken as a first order 225 process, the rate constant is $\sim 0.17 \mathrm{~h}^{-1}$.

Ultimately AuNCs proved the most compliant material, as AuNSs showed significant 227 responses to salinity, which is attributed to the electrostatic stabilization of the citrate capping228 ligand, and AuNRs showed a tendency to agglomerate and not adhere to the surface, which is 229 attributed to the enduring and contrary nature of the cetyl trimethyl ammonium bromide (CTAB) 230 coating. Particle coated surfaces were successfully generated with controllable surface coverage 231 using moderate adjustments to Scheme 1. Adjustments of individual parameters were necessary 232 depending on particle type (Table 1). The most significant changes were made to the salinity and $233 \mathrm{pH}$ of the reaction solution. AuNSs, AuNRs, and AuNCs were successfully and uniformly adhered 234 to surfaces (Fig. 4).

The AuNC coated surfaces were thermally treated with a continuous wave (CW) $808 \mathrm{~nm}$ 236 laser $\left(0.25-1.25 \mathrm{~W} / \mathrm{cm}^{2}\right)$, and a thermal couple was used to measure the temperature at the glass 237 surface in wells containing $1 \mathrm{~mL}$ cell culture media, which was used as the bulk temperature of 238 the media. The temperature change was shown to be dependent on both the laser fluence and the 239 coverage density (Fig. 5 A, B). SEM imaging following laser treatment revealed some 240 morphological changes, but the gross nanocage structure remained intact (Fig. 5 C, D). It is unclear 241 whether these changes are the result of nanomaterial restructuring, or carbonization of the coating 242 materials and/or adsorbed proteinaceous material from the medium 
Theoretical modeling was performed to estimate the temperature profile as a function of 244 distance from the AuNC coated surfaces into the media. From Eq. (3), it can be seen that the 245 difference between a planar distribution of multiple nanoparticle heat sources compared to a single 246 nanoparticle heat source is the factor $R_{N P} N_{N P}^{(m-1) / m} / p$. Thus, the heat source $Q$ can rather be 247 considered an effective heat source $\bar{Q}=Q R_{N P} N_{N P}^{(m-1) / m} / p$ to be used in Eq. (2). The temperature 248 change versus $r$ (Fig. 6A) was calculated assuming $V_{N P}=(0.05 \mu \mathrm{m})^{3}$ and $k=6 \mathrm{e}-7 \mathrm{~W} / \mu \mathrm{m} / \mathrm{K}$. It 249 was found that an effective heat source of $\bar{Q}=1 \mathrm{~W} / \mu \mathrm{m}^{3}$ resulted in a temperature change of $8.3^{\circ} \mathrm{C}$ 250 at a distance of $2 \mu \mathrm{m}$ from the surface. This temperature change is well within the range of 251 measured values from the experiments (Fig. 5 A,B), thus giving confidence to this chosen value 252 of $\bar{Q}$. With the given values, the maximal temperature change occurring at the surface predicted 253 by the model is $330{ }^{\circ} \mathrm{C}$. The temperature change curve shown in Fig. 6A can be changed to a 254 temperature curve by adding the far-field temperature of medium, labeled here as $\mathrm{T}_{\infty}$. Assuming 255 the far-field temperature within the wells is gradually increasing with time, a set of temperature 256 curves can be plotted (Fig. 6B). The far-field temperature values were taken from the experimental 257 measurements for $54 \mathrm{AuNC} / \mu^{2}$ and $0.75 \mathrm{~W} / \mathrm{cm}^{2}$ irradiation. Temperatures near the coated 258 surface are affected minimally from the gradual increase in the far-field temperatures. Based on 259 these measurements and the assumption that the cell has a vertical height of $5 \mu \mathrm{m}$ CEM43 values 260 for a given cell in contact with nanocages were calculated (Fig. 6C) for each of the measured 261 temperatures and treated as a Riemann sum (2 min intervals). These values show a thermal dose 262 to adherent cells that far exceeds the values anticipated based on bulk measurements. Murine breast carcinoma cells (4T1) or murine leukemia cells (EL4) were grown on the sterilized surfaces. 4T1 cells are adherent cells while EL4 cells are suspension cells, both have 265 reported doubling times of $\sim 24 \mathrm{~h}$. These cells were grown on surfaces with varying coverage 
266 density of AuNCs and then treated with $0.75 \mathrm{~W} / \mathrm{cm}^{2}$ of $808 \mathrm{~nm}$ laser, which based on the above 267 measurements, yielded a maximum temperature in the medium of $43{ }^{\circ} \mathrm{C}$ after 10 min (Fig. 7A).

268 Cells were also cultured in standard tissue culture plates and treated in a water bath for $1 \mathrm{~h}$ at 42

$269{ }^{\circ} \mathrm{C}$ or $10 \mathrm{~min}$ at $43{ }^{\circ} \mathrm{C}$. The EL4 cells were found to respond similarly regardless of whether the 270 heat source was external water bath-induced bulk heating or laser induced photothermal heating.

271 The 4T1 cells, however, showed a much greater response to the photothermal heating than to the 272 bulk heating. Additionally, cells were independently treated with water bath heating for 10 min at 273 temperatures up to $50{ }^{\circ} \mathrm{C}$ (Fig. 7B). The $4 \mathrm{~T} 1$ cellular response to $10 \mathrm{~min}$ of photothermal treatment 274 was similar to 10 min nearly $50{ }^{\circ} \mathrm{C}$ in the case of $4 \mathrm{~T} 1$ cells, which suggests better alignment with 275 the CEM43 estimate than the measured temperature.

277 Discussion

278 This solution phase deposition provided reliably uniform surfaces. Lithographic techniques 279 have been demonstrated to produce surfaces with a higher degree of uniformity, ${ }^{36}$ but the method 280 used here enables extremely easy scale up, obviates the need to expensive equipment, and can be 281 used with any particle morphology. A variety of parameters were tested to identify optimal 282 conditions for evenly fabricated attachment of different types of nanoparticles onto the silanized 283 coverslips. Factors such as reaction solution, silane concentration, $\mathrm{pH}$, temperature, and duration 284 of nanoparticle-functionalized glass reaction were considered. The coverslips were treated with 285 different concentrations of silanes to maximize the attachment of nanoparticles on the surfaces. As 286 the concentration of silane was increased from $0-10 \%$ in methanol, the number of nanoparticles 287 that attached to the surface increased, and the coverage became saturated at silane concentrations 288 above 10\%. Different reaction buffers such as bicarbonate, carbonate, phosphate, and carbonate- 
bicarbonate buffer were tested to control the density and aggregation of nanoparticles onto glass coverslips. The carbonate-bicarbonate buffer showed the best outcome compared to the other buffers, likely because of its high buffering capacity at $\mathrm{pH} 9$. This buffer proved to be particularly effective at higher $\mathrm{pH}$, which is likely a result of the increased bonding of Au-thiolate relative to Au-thiol. ${ }^{37,38}$ However, at extremely high $\mathrm{pH}(>12)$ or salinity $(>20 \mathrm{mM})$, increases in areas of nanoparticle aggregation were observed. The $\mathrm{pH}$ was determined to be the most critical factor in efficient, high density coating. The strength of the binding can be partly attributed to the large number of Au-S bonds between each particle and the surface. There were also two relevant observations for which we cannot fully account. First, there was significant batch-to-batch variation observed in the coverage density when we used commercially available particles (rods and spheres, specifically) regardless of the surface coating (e.g. PEG, citrate, CTAB). Second, inhouse synthesized AuNCs were significantly more agreeable to work with than commercially available PVP-coated particles, which proved to be inconsistent, prone to aggregation, and to yield lower coverage density.

These results clearly demonstrate that in order to understand different nanomedicine platforms, the experimental setup must be very tightly controlled to elucidate the true interactions and dose response requirements. With regard to the photothermal studies presented here, consider a $0.25 \mathrm{nM}$ solution of (cubic) gold nanocages with a $50 \mathrm{~nm}$ edge length. These particles will ultimately occupy $0.002 \%$ of the solution volume, which means $1 \mathrm{~mL}$ of solution will contain only $20 \mathrm{~nL}$ of nanoparticles; yet these particles can achieve extraordinary thermal effects, despite their volume. By analogy, a kitchen stove can be used to heat an entire dwelling, but the temperature at the stovetop is much greater than the bulk temperature change of the residence, ergo the bulk temperature change is not indicative of the locoregional heating. Furthering the analogy, 
312 to fry an egg, one must put a skillet directly on the stove, rather than merely adjacent, i.e. the 313 immediate biological effects, such as protein denaturation, are likely the result of the close 314 proximity to an extremely hot material, rather than bulk thermal changes. The particle system 315 modeled here represents only a one-dimensional interaction between the surface and the medium. 316 The particles themselves are spaced out on the surface generating further localized hot spots that 317 likely result in significant membrane damage peppered across one side of the cell, and the intensity 318 of these hot spots can be further controlled by varying the laser power density. The sharp increase 319 in temperature as the particle surface is approached results in the cell observing a significantly 320 higher local temperature than can be measured in bulk. As a result, calculations of CEM43 yield 321 orders of magnitude greater thermal dose than based on measured temperatures. These CEM43 322 values align more closely with the biological results for adherent cells, while the suspension cells 323 are aligned more closely with bulk temperature measurements. The steep rise in the predicted 324 temperature at the particle surface provide some explanation for the increased efficacy of targeted 325 nanomaterials in tumor treatment, as these particles are not merely in the interstitium but closely 326 bound to the cell, which amplifies the damage.

As nanomaterials are continually becoming integrated into biological studies, assessing the unique and individual properties of each becomes increasingly important. Each cell will likely 329 interact with a different number of nanoparticles, which could significantly skew results. These 330 surfaces allow a means to normalize this variance to membrane area, and our methodology is 331 widely adaptable to a variety of materials. This platform can be used as a screening platform to 332 more precisely define the thermosensitivity of various cell lines. Our chosen application was 333 photothermal killing of cancer cells, but there are many other avenues available. There are many 334 nanoparticle-bound drug complexes in development, and these surfaces could be adapted to 
335 provide insight into their efficacy. There is heated debate about the nanoparticle dose required to

336 provide effective radiosensitization, which is further confounded by the variety of particles studied

337 in various research labs. Additionally, these surfaces can be used to explore the topological effects

338 on cell growth and differentiation, and application of reduced laser doses can be used to potentially

339 drive differentiation in key directions. Ultimately, these types of surfaces allow for control of some

340 of the variables at play in nanomedicine. They present an avenue for greater understanding of the

341 interactions at the interface between nanotechnology and biology.

\section{Conclusion}

343 Generating surfaces of known particle density allowed for more accurate determination of the 344 effect of nanoregional heating in the current study. By coating the particles on the surface, the 345 number of particles directly contacting each cell can be more tightly controlled and the number of 346 particles per unit area of the membrane can be optimized for a given experimental goal. The

347 fabrication method we have developed for our cell cultures securely attaches gold nanoparticles to 348 glass. This method's utility was demonstrated with a variety of nanoparticle morphologies 349 including $\mathrm{Au}$ nanocages, nanorods, and nanospheres. SEM validated a uniform distribution, 350 particularly in relation to the size of a mammalian cell. Nanocages that were roughly $50 \mathrm{~nm}$ across 351 were used as a model system to demonstrate the highly localized effects of nanoparticle heating 352 by absorption of near infrared laser and the failure of bulk temperature measurements to accurately 353 predict outcomes. The nanomaterial coated surfaces appear to be useful for a variety of in vitro, 354 pre-clinical investigations and ultimately may predict in vivo performance of various 355 nanomedicines.

\section{Declarations}

357 Ethics Approval and Consent to Participate 
358 This work did not include or animal subject. Experiments were performed in compliance with

359 institutional biosafety and biosecurity protocols.

360 Consent for Publication

361 No images of human subjects are included in this work.

362 Availability of Data and Material

363 Data sharing is not applicable to this article as no datasets were generated or analysed during the 364 current study.

365 Competing Interests

366 The Authors declare no competing financial interest

$367 \quad$ Funding

368 Funding for this work was provided by National Science Foundation EPSCoR RIII Award 3691457888 and the Translational Research Institute grant TL1 TR003109 through the National 370 Center for Advancing Translational Sciences of the National Institutes of Health (NIH).

371 Authors' Contributions

372 SVJ: Conceptualization, Methodology, Investigation, Writing Original Draft, Review Editing,

373 SJ: Methodology, Investigation, Writing Original Draft, Writing Review Editing

374 SS: Investigation

375 PM: Methodology, Investigation, Writing original draft, Writing review editing

376 RD: Conceptualization, Resources, Writing Review editing, Supervision

377 MB: Conceptualization, Methodology, Resources, Writing review editing, Supervision, Funding 378 Acquisition

379 RG: Conceptualization, Methodology, Resources, Writing Original Draft, Review Editing, 380 Supervision, Funding Acquisition 
382 The authors thank J. Chen for providing facilities for AuNC synthesis, P. Corry, N. Koonce, and

383 J. Bischof for helpful discussion.

\section{REFERENCES}

385 1. Sharma, S. K.; Shrivastava, N.; Rossi, F.; Tung, L. D.; Thanh, N. T. K., Nanoparticles386 based magnetic and photo induced hyperthermia for cancer treatment. Nano Today 2019, 29, 387100795.

$388 \quad 2 . \quad$ Wilets, K. A.; Duyne, R. P. V., Localized Surface Plasmon Resonance Spectroscopy and 389 Sensing. Annual Review of Physical Chemistry 2007, 58, 267-97.

$390 \quad 3 . \quad$ Schöttler, S.; Becker, G.; Winzen, S.; Steinbach, T.; Mohr, K.; Landfester, K.;

391 Mailänder, V.; Wurm, F. R., Protein adsorption is required for stealth effect of poly(ethylene 392 glycol)- and poly(phosphoester)-coated nanocarriers. Nature Nanotechnology 2016, 11, 372.

393 4. Zhou, J.; Ralston, J.; Sedev, R.; Beattie, D. A., Functionalized gold nanoparticles:

394 Synthesis, structure and colloid stability. Journal of Colloid and Interface Science 2009, 331 (2), $395 \quad 251-262$.

$396 \quad 5 . \quad$ Srivatsan, A.; Jenkins, S. V.; Jeon, M.; Wu, Z.; Kim, C.; Chen, J.; Pandey, R. K., Gold 397 nanocage-photosensitizer conjugates for dual-modal image-guided enhanced photodynamic 398 therapy. Theranostics 2014, 4 (2), 163-74.

399 6. Jenkins, S. V.; Qu, H.; Mudalige, T.; Ingle, T. M.; Wang, R.; Wang, F.; Howard, P. 400 C.; Chen, J.; Zhang, Y., Rapid determination of plasmonic nanoparticle agglomeration status in 401 blood. Biomaterials 2015, 51 (0), 226-237. 
$4027 . \quad$ Wang, H.; Chen, B.; He, M.; Li, X.; Chen, P.; Hu, B., Study on uptake of gold 403 nanoparticles by single cells using droplet microfluidic chip-inductively coupled plasma mass 404 spectrometry. Talanta 2019, 200, 398-407.

405 8. Rosman, C.; Pierrat, S.; Henkel, A.; Tarantola, M.; Schneider, D.; Sunnick, E.; 406 Janshoff, A.; Sönnichsen, C., A New Approach to Assess Gold Nanoparticle Uptake by 407 Mammalian Cells: Combining Optical Dark-Field and Transmission Electron Microscopy. Small $408 \quad$ 2012, $8(23), 3683-3690$.

409 9. Jenkins, S. V.; Nima, Z. A.; Vang, K. B.; Kannarpady, G.; Nedosekin, D. A.; Zharov, 410 V. P.; Griffin, R. J.; Biris, A. S.; Dings, R. P. M., Triple-negative breast cancer targeting and 411 killing by EpCAM-directed, plasmonically active nanodrug systems. npj Precision Oncology $412 \quad 2017,1(1), 27$.

413 10. Yuan, H.; Fales, A. M.; Vo-Dinh, T., TAT Peptide-Functionalized Gold Nanostars: 414 Enhanced Intracellular Delivery and Efficient NIR Photothermal Therapy Using Ultralow 415 Irradiance. Journal of the American Chemical Society 2012, 134 (28), 11358-11361.

416 11. Untener, E. A.; Comfort, K. K.; Maurer, E. I.; Grabinski, C. M.; Comfort, D. A.; 417 Hussain, S. M., Tannic Acid Coated Gold Nanorods Demonstrate a Distinctive Form of 418 Endosomal Uptake and Unique Distribution within Cells. ACS Applied Materials \& Interfaces 419 2013, 5 (17), 8366-8373.

420 12. Gu, Y.-J.; Cheng, J.; Lin, C.-C.; Lam, Y. W.; Cheng, S. H.; Wong, W.-T., Nuclear 421 penetration of surface functionalized gold nanoparticles. Toxicology and Applied Pharmacology 422 2009, 237 (2), 196-204. 
423 13. Merzel, R. L.; Orr, B. G.; Banaszak Holl, M. M., Distributions: The Importance of the 424 Chemist's Molecular View for Biological Materials. Biomacromolecules 2018, 19 (5), 1469 4251484.

426 14. Coradeghini, R.; Gioria, S.; García, C. P.; Nativo, P.; Franchini, F.; Gilliland, D.;

427 Ponti, J.; Rossi, F., Size-dependent toxicity and cell interaction mechanisms of gold

428 nanoparticles on mouse fibroblasts. Toxicology Letters 2013, 217 (3), 205-216.

429 15. Haiss, W.; Thanh, N. T. K.; Aveyard, J.; Fernig, D. G., Determination of Size and

430 Concentration of Gold Nanoparticles from UV-Vis Spectra. Analytical Chemistry 2007, 79 (11), $431 \quad 4215-4221$.

432 16. Zlatanova, J.; van Holde, K., Single-Molecule Biology: What Is It and How Does It 433 Work? Molecular Cell 2006, 24 (3), 317-329.

434 17. Ali, M. R. K.; Wu, Y.; El-Sayed, M. A., Gold-Nanoparticle-Assisted Plasmonic 435 Photothermal Therapy Advances Toward Clinical Application. The Journal of Physical 436 Chemistry C 2019, 123 (25), 15375-15393.

437 18. Dewey, W. C., Arrhenius relationships from the molecule and cell to the clinic.

438 International Journal of Hyperthermia 1994, 10 (4), 457-483.

439 19. Pearce, J., Relationship between Arrhenius models of thermal damage and the CEM 43

440 thermal dose. SPIE: 2009; Vol. 7181.

441 20. Behrouzkia, Z.; Joveini, Z.; Keshavarzi, B.; Eyvazzadeh, N.; Aghdam, R. Z.,

442 Hyperthermia: How Can It Be Used? Oman Medical Journal 2016, 31 (2), 89-97.

443 21. Creixell, M.; Bohórquez, A. C.; Torres-Lugo, M.; Rinaldi, C., EGFR-Targeted Magnetic 444 Nanoparticle Heaters Kill Cancer Cells without a Perceptible Temperature Rise. ACS Nano 2011, $445 \quad 5(9), 7124-7129$. 
446 22. Gerner, E. W., Thermal dose and time - temperature factors for biological responses to 447 heat shock. International Journal of Hyperthermia 1987, 3 (4), 319-327.

$448 \quad 23 . \quad$ van Rhoon, G. C.; Samaras, T.; Yarmolenko, P. S.; Dewhirst, M. W.; Neufeld, E.;

449 Kuster, N., CEM $43^{\circ} \mathrm{C}$ thermal dose thresholds: a potential guide for magnetic resonance

450 radiofrequency exposure levels? European radiology 2013, 23 (8), 2215-2227.

451 24. Borrelli, M. J.; Thompson, L. L.; Cain, C. A.; Dewey, W. C., Time-temperature analysis 452 of cell killing of BHK cells heated at temperatures in the range of $43.5^{\circ} \mathrm{C}$ to $57.0^{\circ} \mathrm{C}$.

453 International Journal of Radiation Oncology*Biology*Physics 1990, 19 (2), 389-399.

454 25. Garanina, A. S.; Naumenko, V. A.; Nikitin, A. A.; Myrovali, E.; Petukhova, A. Y.;

455 Klimyuk, S. V.; Nalench, Y. A.; Ilyasov, A. R.; Vodopyanov, S. S.; Erofeev, A. S.; Gorelkin,

456 P. V.; Angelakeris, M.; Savchenko, A. G.; Wiedwald, U.; Majouga Dr, A. G.; Abakumov, M.

457 A., Temperature-controlled magnetic nanoparticles hyperthermia inhibits primary tumor growth 458 and metastases dissemination. Nanomedicine: Nanotechnology, Biology and Medicine 2020, 459102171.

460 26. Li, Z.; Huang, P.; Zhang, X.; Lin, J.; Yang, S.; Liu, B.; Gao, F.; Xi, P.; Ren, Q.; Cui, 461 D., RGD-Conjugated Dendrimer-Modified Gold Nanorods for in Vivo Tumor Targeting and 462 Photothermal Therapy. Molecular Pharmaceutics 2010, 7 (1), 94-104.

463 27. Zhang, S.; Li, Y.; He, X.; Dong, S.; Huang, Y.; Li, X.; Li, Y.; Jin, C.; Zhang, Y.;

464 Wang, Y., Photothermolysis mediated by gold nanorods modified with EGFR monoclonal 465 antibody induces Hep-2 cells apoptosis in vitro and in vivo. International journal of 466 nanomedicine 2014, 9, 1931-1946.

467 28. Jenkins, S. V.; Nedosekin, D. A.; Shaulis, B. J.; Wang, T.; Jamshidi-Parsian, A.; 468 Pollock, E. D.; Chen, J.; Dings, R. P. M.; Griffin, R. J., Enhanced Photothermal Treatment 
Efficacy and Normal Tissue Protection via Vascular Targeted Gold Nanocages.

$470 \quad$ Nanotheranostics 2019, 3 (2), 145-155.

471 29. Jenkins, S. V.; Nedosekin, D. A.; Miller, E. K.; Zharov, V. P.; Dings, R. P. M.; Chen,

472 J.; Griffin, R. J., Galectin-1-based tumour-targeting for gold nanostructure-mediated

473 photothermal therapy. International Journal of Hyperthermia 2018, 34 (1), 19-29.

$474 \quad 30 . \quad$ Meeker, D. G.; Jenkins, S. V.; Miller, E. K.; Beenken, K. E.; Loughran, A. J.;

475 Powless, A.; Muldoon, T. J.; Galanzha, E. I.; Zharov, V. P.; Smeltzer, M. S.; Chen, J.,

476 Synergistic Photothermal and Antibiotic Killing of Biofilm-Associated Staphylococcus aureus

477 Using Targeted Antibiotic-Loaded Gold Nanoconstructs. ACS Infectious Diseases 2016, 2 (4),

$478 \quad 241-250$.

479 31. Zhang, Y.; Zhan, X.; Xiong, J.; Peng, S.; Huang, W.; Joshi, R.; Cai, Y.; Liu, Y.; Li, 480 R.; Yuan, K.; Zhou, N.; Min, W., Temperature-dependent cell death patterns induced by 481 functionalized gold nanoparticle photothermal therapy in melanoma cells. Scientific Reports $482 \quad 2018,8(1), 8720$.

483 32. Carlson, M. T.; Khan, A.; Richardson, H. H., Local Temperature Determination of 484 Optically Excited Nanoparticles and Nanodots. Nano Letters 2011, 11 (3), 1061-1069.

485 33. Baffou, G.; Berto, P.; Bermúdez Ureña, E.; Quidant, R.; Monneret, S.; Polleux, J.;

486 Rigneault, H., Photoinduced Heating of Nanoparticle Arrays. ACS Nano 2013, 7 (8), 6478-6488.

487 34. Skrabalak, S. E.; Au, L.; Li, X.; Xia, Y., Facile synthesis of Ag nanocubes and Au 488 nanocages. Nat Protoc 2007, 2 (9), 2182-90.

489 35. Govorov, A. O.; Zhang, W.; Skeini, T.; Richardson, H.; Lee, J.; Kotov, N. A., Gold 490 nanoparticle ensembles as heaters and actuators: melting and collective plasmon resonances. $491 \quad$ Nanoscale Research Letters 2006, 1 (1), 84. 
492 36. van Dommelen, R.; Fanzio, P.; Sasso, L., Surface self-assembly of colloidal crystals for 493 micro- and nano-patterning. Advances in Colloid and Interface Science 2018, 251, 97-114.

494 37. Xue, Y.; Li, X.; Li, H.; Zhang, W., Quantifying thiol-gold interactions towards the 495 efficient strength control. Nature Communications 2014, 5, 4348.

496 38. Ansar, S. M.; Ameer, F. S.; Hu, W.; Zou, S.; Pittman, C. U.; Zhang, D., Removal of

497 Molecular Adsorbates on Gold Nanoparticles Using Sodium Borohydride in Water. Nano Letters $498 \quad 2013,13(3), 1226-1229$.

\section{$499 \quad$ Figure Captions}

500 Table 1 - Synthetic Parameters and outcomes.

501

502 Scheme 1 - Fabrication of strongly bound AuNP-coated glass coverslips.

503

504

Figure 1 - Optical characterization of AuNC coated surfaces. (A) Photograph of AuNC-coated 505 surfaces with varying coverage densities. (B-E) Optical microscopy (10x magnification) of the 506 coated surfaces). (F) Extinction spectra of coated surfaces with varying densities.

507

508

Figure 2 - Scanning electron microscopy and quantification of AuNC coated surfaces. Reaction 509 AuNC quantities and resultant coverage densities (mean \pm s.d.) of (A) 0, 0; (B) 6.4 fmol, $20 \pm 2$ $\mathrm{AuNC} / \mu \mathrm{m}^{2}$; (C) $12.8 \mathrm{fmol}, 32 \pm 2 \mathrm{AuNC} / \mu \mathrm{m}^{2}$; (D) $25.6 \mathrm{fmol}, 54 \pm 2 \mathrm{AuNC} / \mu \mathrm{m}^{2}$.

Figure 3 Kinetics of AuNC deposition. (A) Extinction spectra, (B) coverage density (mean \pm s.d.), 513 and (C) corresponding SEM for AuNC coated surfaces generated using 12.8 fmol AuNC. 
515 Figure 4 - Scanning Electron microscopy of other AuNP morphologies. (A) Au rods (11x47 nm),

516 (B) $50 \mathrm{~nm}$ Au spheres, (C) $5 \mathrm{~nm}$ Au spheres with $100 \mathrm{~nm}$ scale bars.

518 Figure 5 - Laser heating of AuNC coated surfaces. (A) Surface temperature of the $32 \mathrm{AuNC} / \mu \mathrm{m}^{2}$

519 coated surface with varying laser output. (B) Surface temperature during $1.5 \mathrm{~W}\left(0.75 \mathrm{~W} / \mathrm{cm}^{2}\right)$

520 irradiation with AuNC coated surface of varying coverage density. SEM images of AuNC coated 521 surfaces after thermal treatment (C) before and (D) after rinsing with DMSO. Data presented are 522 mean \pm s.d.

523

524 Figure 6 - Theoretical calculations of temperature versus distance from the AuNC-coated surface.

525 (A) Temperature change versus distance as calculated from Eq. (3). The inset shows the same 526 curve but with a smaller range of distance. (B) Temperature versus distance for increasing time.

527 The temperature values were calculated by adding the shown $\mathrm{T}_{\infty}$ values for each time to the 528 temperature change curve shown in (A). The inset shows the same curves but with a smaller range 529 of distance. (C) Theoretical thermal dose (cumulative equivalent minutes at $43{ }^{\circ} \mathrm{C}$; CEM43) based 530 on average temperature experienced across $5 \mu \mathrm{m}$ outward from the particle surface.

531

532 Figure 7 - Cell viability as a function of heating. (A) Viability of EL4 (crossed, red) and 4T1 533 (slashed, blue) cells following laser irradiation or bulk heating normalized to untreated cells on a 534 standard tissue culture plate. (B) Viability response of 4T1 cells to bulk heating for 10 min. Data 535 presented are mean \pm s.d. 


\section{Figures}
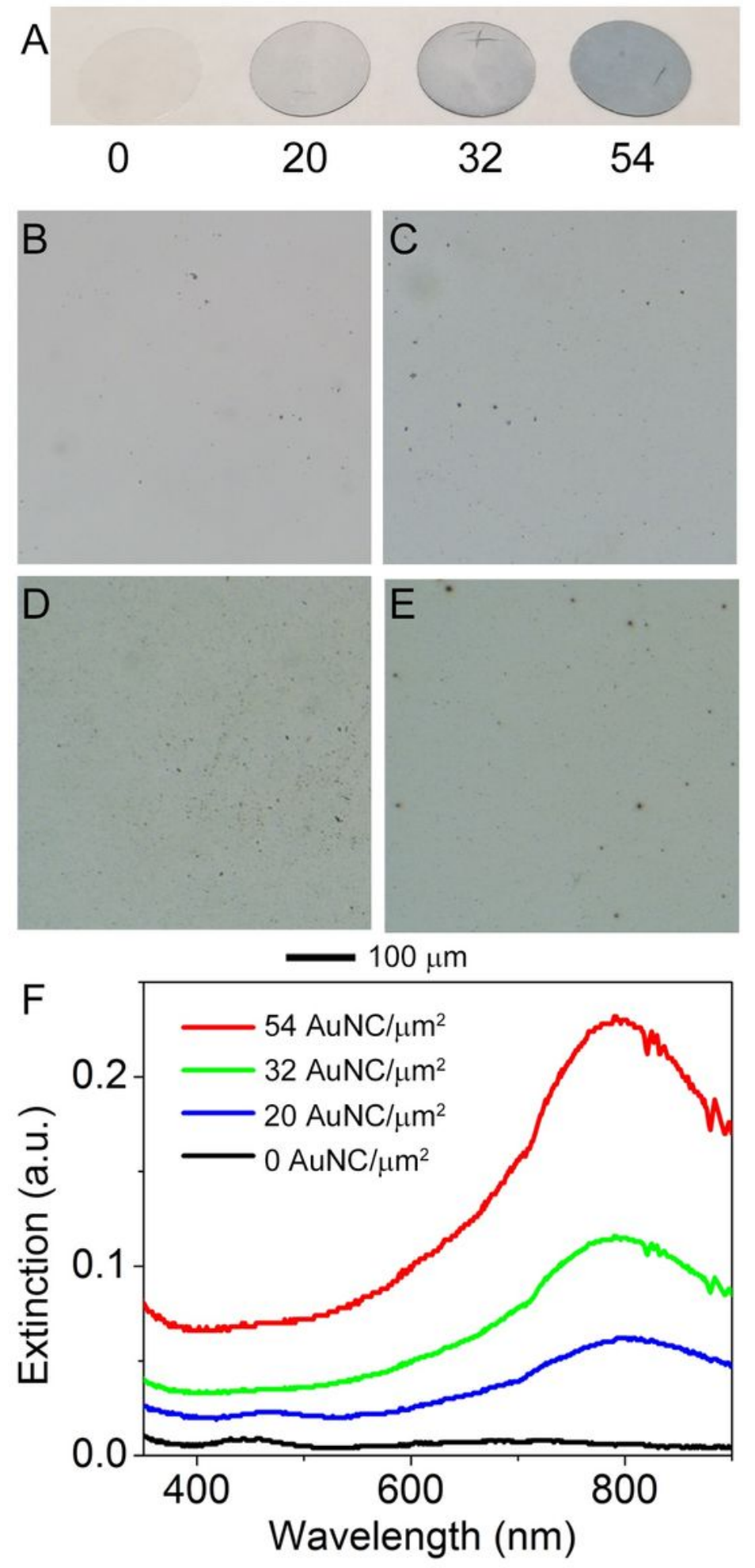

Figure 1

Optical characterization of AuNC coated surfaces. (A) Photograph of AuNC-coated surfaces with varying coverage densities. (B-E) Optical microscopy (10x magnification) of the coated surfaces). (F) Extinction spectra of coated surfaces with varying densities. 


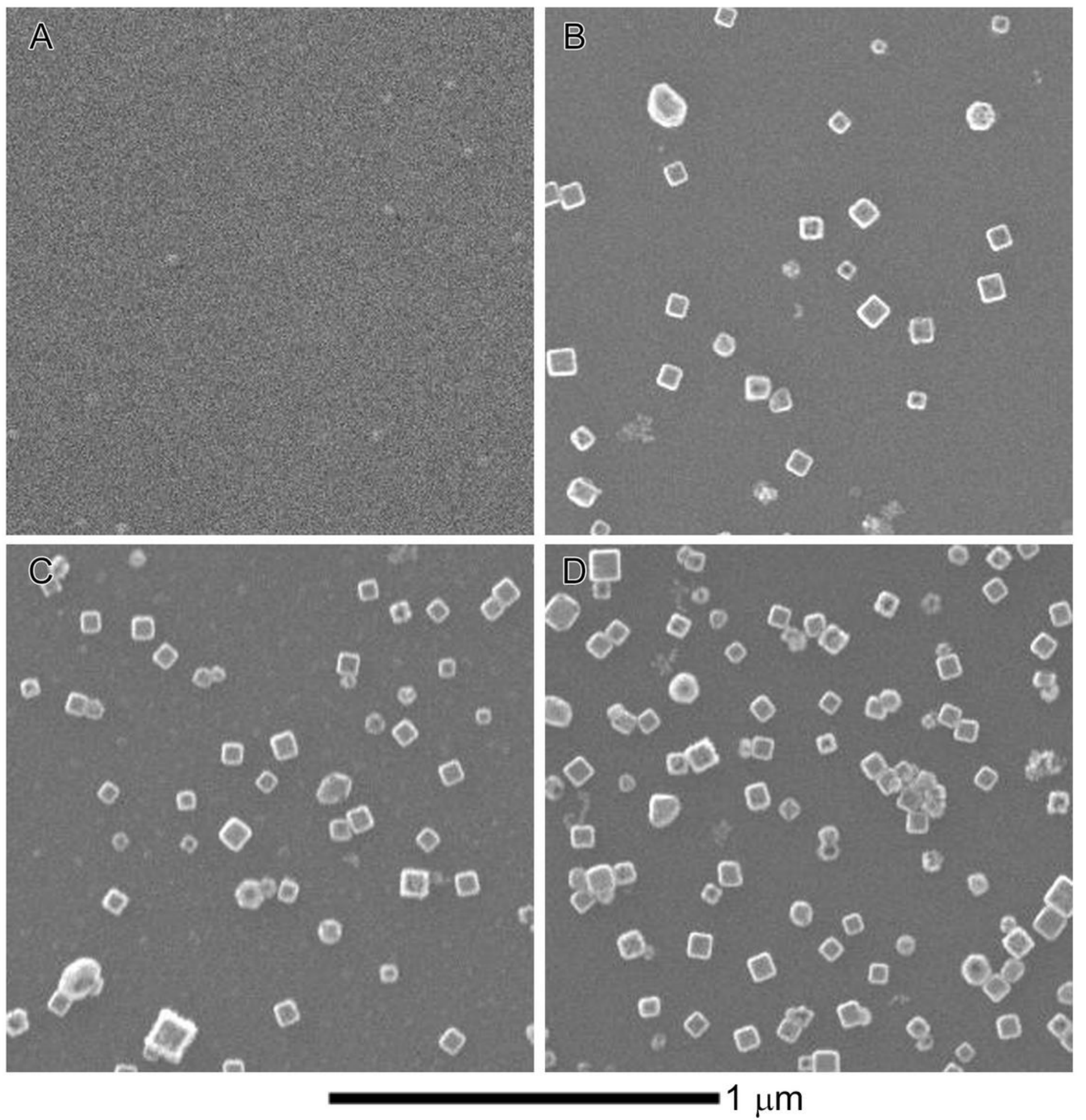

\section{Figure 2}

Scanning electron microscopy and quantification of AuNC coated surfaces. Reaction AuNC quantities and resultant coverage densities (mean $\nabla \mathrm{s}$.d.) of (A) 0, 0; (B) $6.4 \mathrm{fmol}, 20 \otimes 2 \mathrm{AuNC} / \mu \mathrm{m} 2$; (C) $12.8 \mathrm{fmol}$, $32 \otimes 2 \mathrm{AuNC} / \mu \mathrm{m} 2$; (D) $25.6 \mathrm{fmol}, 54 \otimes 2 \mathrm{AuNC} / \mu \mathrm{m} 2$. 

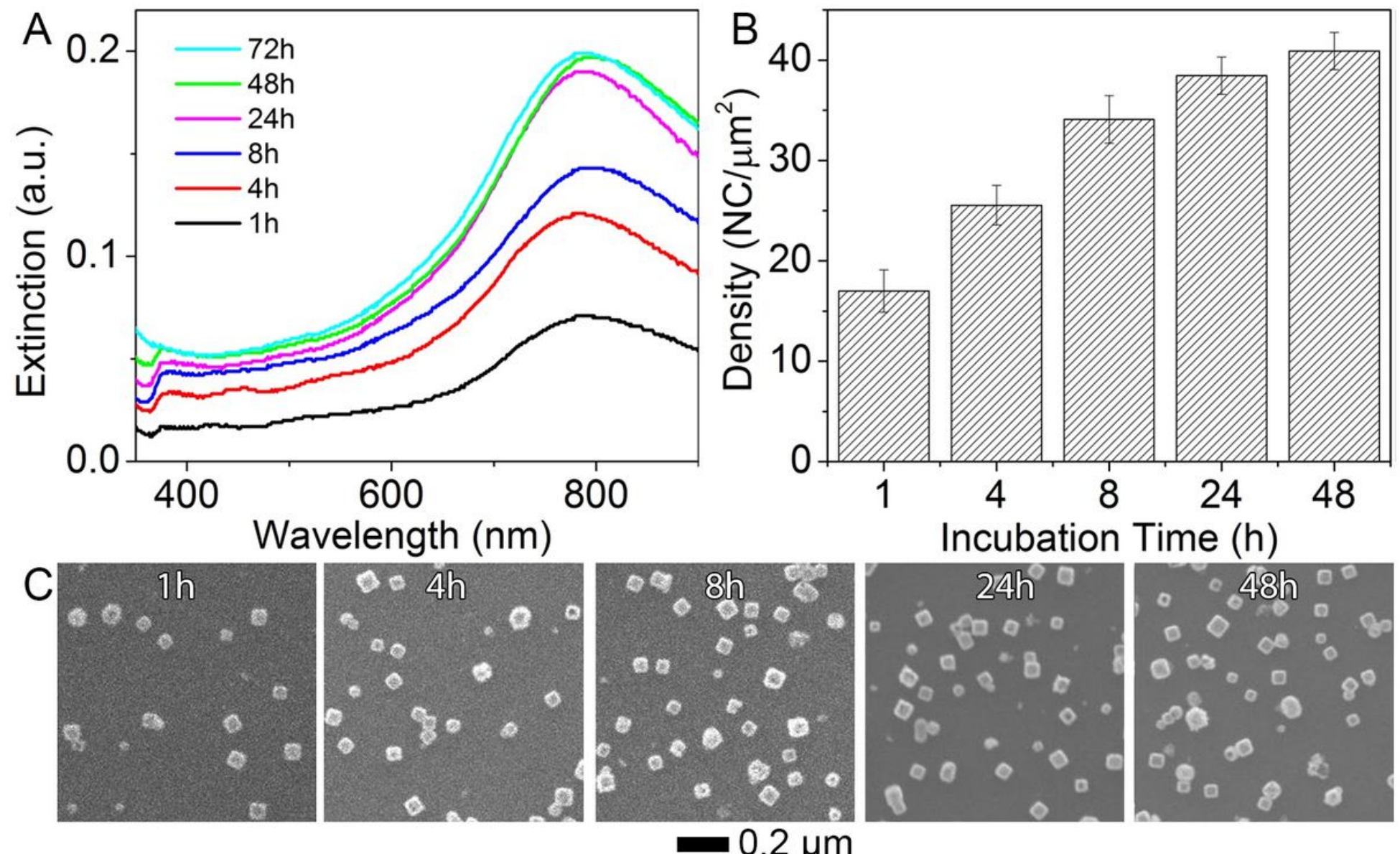

$0.2 \mu \mathrm{m}$

Figure 3

Kinetics of AuNC deposition. (A) Extinction spectra, (B) coverage density (mean \pm s.d.), and (C) corresponding SEM for AuNC coated surfaces generated using $12.8 \mathrm{fmol}$ AuNC. 

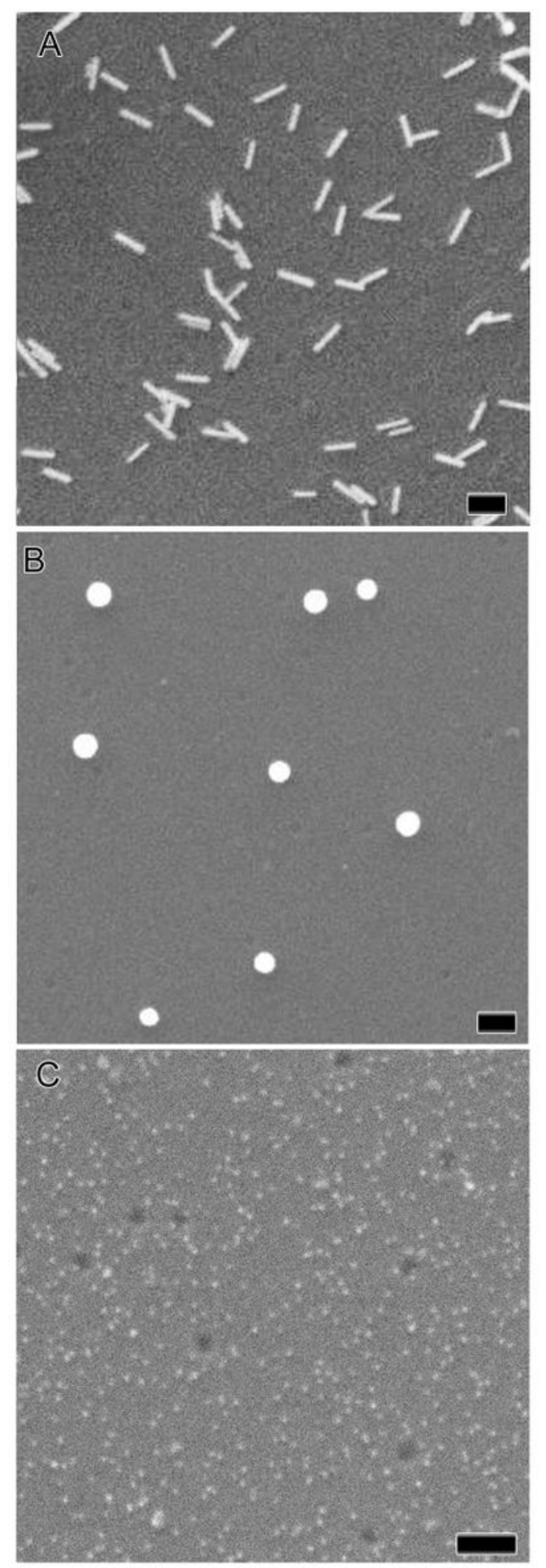

Figure 4

Scanning Electron microscopy of other AuNP morphologies. (A) Au rods (11x47 nm), (B) $50 \mathrm{~nm}$ Au spheres, (C) $5 \mathrm{~nm}$ Au spheres with $100 \mathrm{~nm}$ scale bars. 

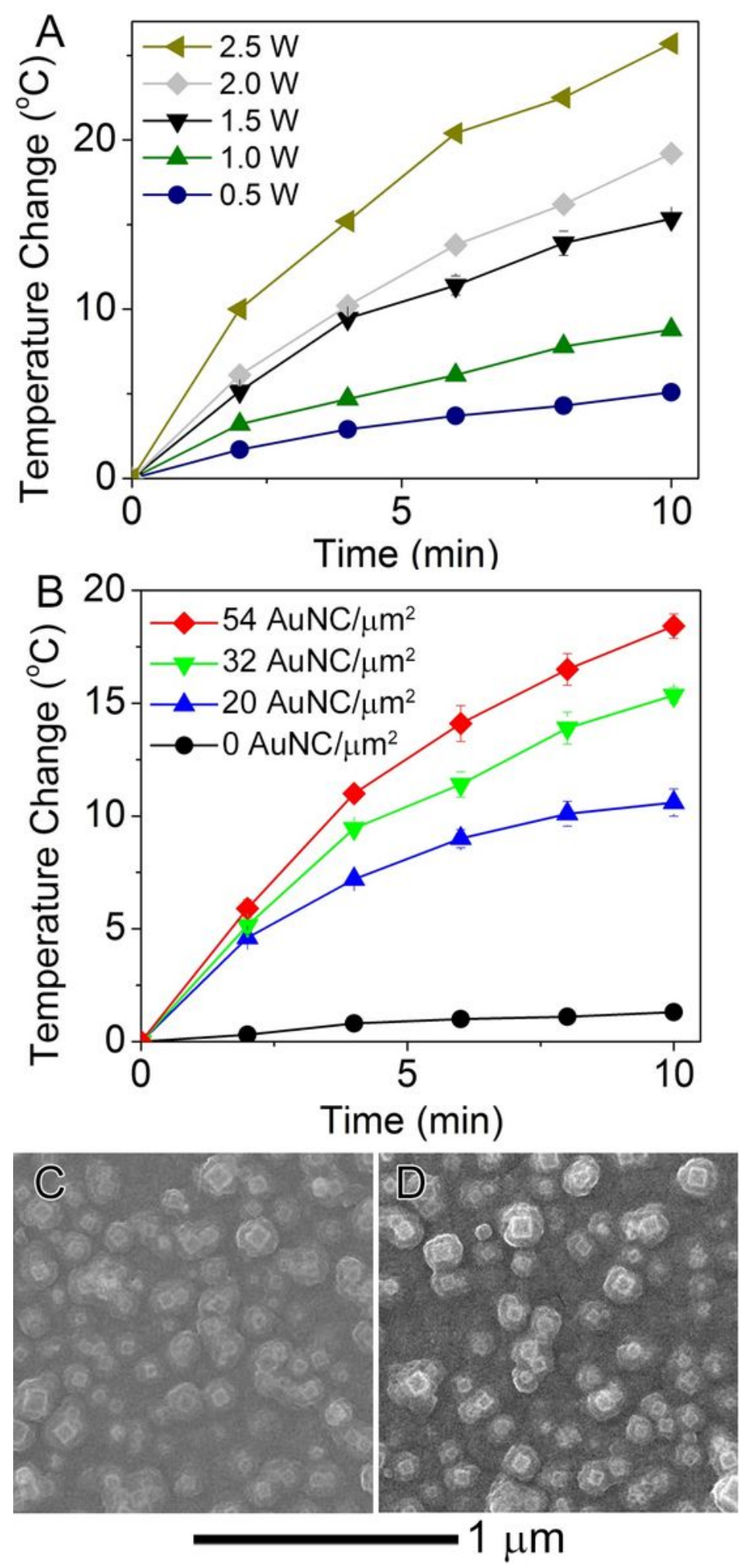

Figure 5

Laser heating of AuNC coated surfaces. (A) Surface temperature of the $32 \mathrm{AuNC} / \mu \mathrm{m} 2$ coated surface with varying laser output. (B) Surface temperature during $1.5 \mathrm{~W}(0.75 \mathrm{~W} / \mathrm{cm} 2)$ irradiation with AuNC coated surface of varying coverage density. SEM images of AuNC coated surfaces after thermal treatment (C) before and (D) after rinsing with DMSO. Data presented are mean \pm s.d. 

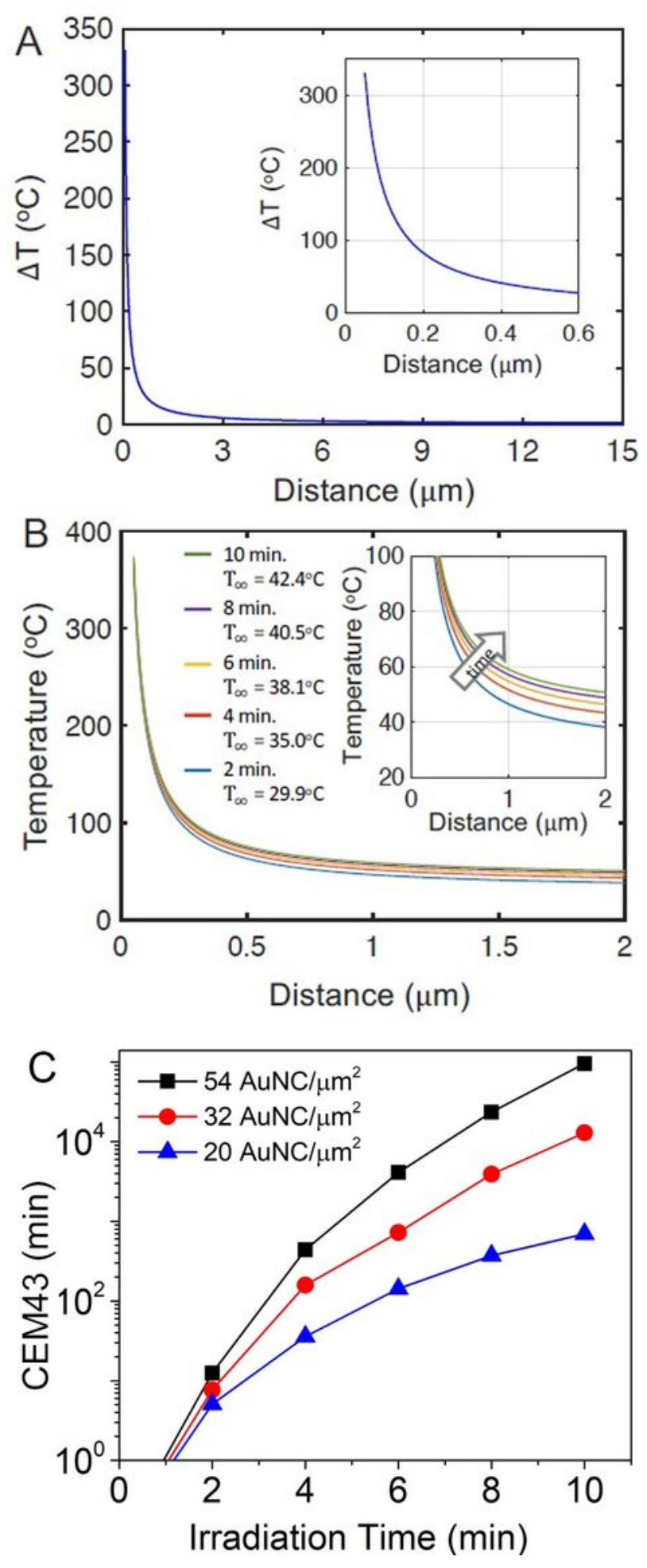

\section{Figure 6}

Theoretical calculations of temperature versus distance from the AuNC-coated surface. (A) Temperature change versus distance as calculated from Eq. (3). The inset shows the same curve but with a smaller range of distance. (B) Temperature versus distance for increasing time. The temperature values were calculated by adding the shown $T_{-}{ }^{\infty}$ values for each time to the temperature change curve shown in (A). The inset shows the same curves but with a smaller range of distance. (C) Theoretical thermal dose 
(cumulative equivalent minutes at $43^{\circ} \mathrm{C}$; CEM43) based on average temperature experienced across $5 \mu \mathrm{m}$ outward from the particle surface.
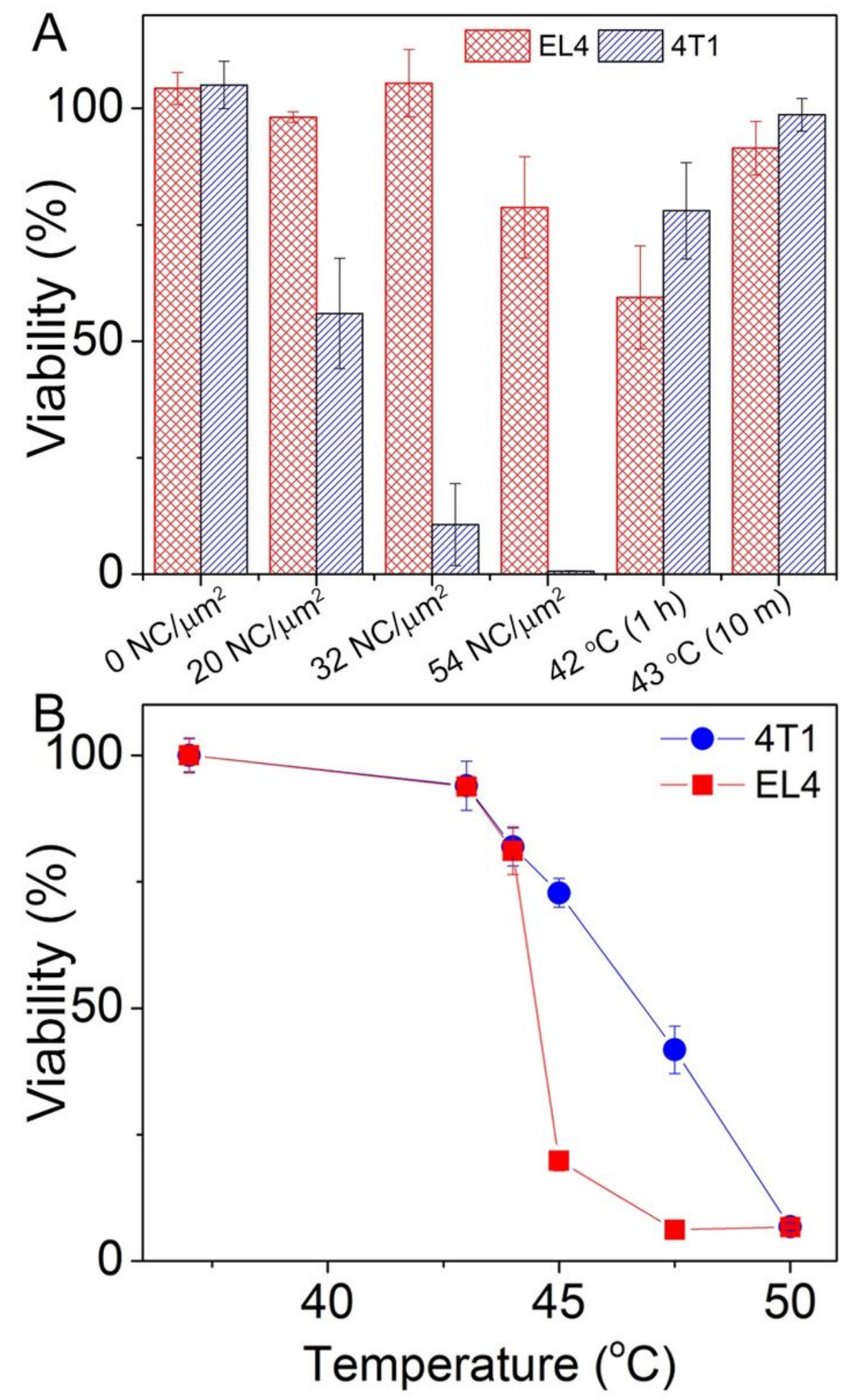

Figure 7

Cell viability as a function of heating. (A) Viability of EL4 (crossed, red) and 4T1 (slashed, blue) cells following laser irradiation or bulk heating normalized to untreated cells on a standard tissue culture plate. (B) Viability response of $4 \mathrm{~T} 1$ cells to bulk heating for $10 \mathrm{~min}$. Data presented are mean \pm s.d. 


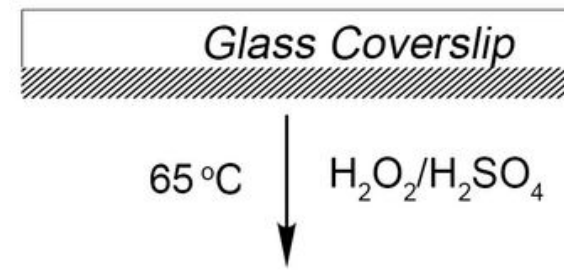

$\mathrm{OH} \mathrm{OH} \mathrm{OH} \mathrm{OH} \mathrm{OH} \mathrm{OH} \mathrm{OH} \mathrm{OH} \mathrm{OH} \mathrm{OH}$
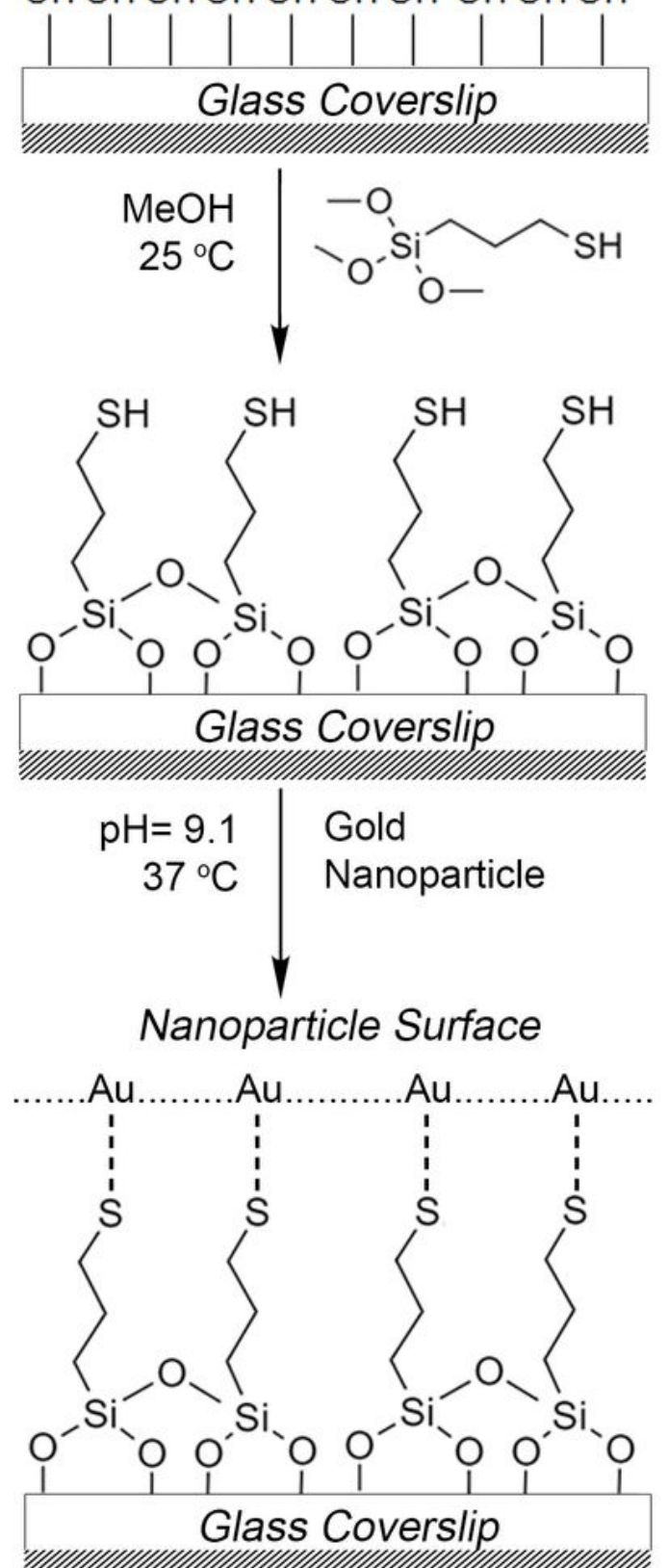

\section{Figure 8}

Scheme 1 - Fabrication of strongly bound AuNP-coated glass coverslips.

\section{Supplementary Files}

This is a list of supplementary files associated with this preprint. Click to download. 
- Table1.pdf 